\title{
REPRESENTAÇÕES DE UNIVERSITÁRIOS SOBRE CULTURAS ORIGINÁRIAS: O DESAFIO DA DESCOLONIZAÇÃO DO CURRÍCULO
}

\author{
Suely Aparecida do Nascimento Mascarenha ${ }^{1}$ \\ Fabiane Maia Garcia ${ }^{2}$ \\ Vilma Aparecida de Pinho ${ }^{3}$ \\ Luis Ernesto Solano Becerril ${ }^{4}$
}

\begin{abstract}
Ubuntu como humanismo africano bantú, entonces, alude a la convivencia con ese otro (ser humano y otros seres). Vivir con ese otro, respetarlo en su diferencia y reconociendo lo valioso que es para mi existencia, para mi vida, me hace más humano, ya que me hace respetuoso, solidario, responsable, compasivo y generoso no sólo para con mis semejantes seres humanos, sino también con la naturaleza. Esto es vivir Ubuntu, esto es ser humano.
\end{abstract}

\section{RESUMO}

As culturas humanas são milenárias integram o conjunto de saberes e cosmovisões da família humana. Integram a identidade dos povos e sua subjetividade social impactando sobre a construção da identidade individual que orienta o comportamento diante das situações cotidianas no âmbito público e privado. Este artigo, parte de uma investigação mais ampla realizada ao abrigo do PROCAD/AMAZONIA, CAPES/UFAM/UFMT/UFPA (Ref. Proc. 8881.314288/2019-0), objetiva apresentar representações de universitários de diferentes países (Brasil, México, Bolívia, Venezuela, Moçambique, Portugal, Espanha, República Dominicana e Colômbia) sobre a valorização das culturas de seus territórios. Participaram da pesquisa, observando procedimentos éticos internacionais $n=881$ universitários do sexo masculino e do sexo feminino. O instrumento próprio contendo questões abertas e fechadas foi respondido por meio da internet com apoio dos pesquisadores convidados. Os resultados demonstram percepção de baixa valorização das culturas originárias por parte dos universitários impactando em descontentamento entre os integrantes dessas culturas. Concluímos pela necessidade da criação de políticas públicas afirmativas para inclusão do estudo das culturas originárias de maneira efetiva nos currículos em geral.

Palavras-chave: Representações. Culturas originárias. Universitários. Currículo escolar.

\footnotetext{
${ }^{1}$ Possui graduação em Pedagogia - Supervisão escolar e magistério pela Universidade Federal de Rondônia (1987) e doutorado em Diagnóstico e avaliação educativa-psicopedagogia pela Universidade da Coruña (2004, revalidado e registrado pela UNB). Concluiu estágio de pós-doutoramento com ênfase em Psicologia Escolar pela Universidade do Minho (2005). É professora DE na Universidade Federal do Amazonas- Campus do Vale do Rio Madeira - Instituto de Educação, Agricultura e Ambiente - IEAA - Humaitá (2006). Coordena grupos de pesquisas UFAM/CNPq (2006), dirige periódicos vinculados aos grupos de pesquisa que lidera: Revistas Educamazônia (2008-atual) e Revista AMAzônica (2008-atual). Coordenou diversos projetos de pesquisas apoiados pelo CNPq e FAPEAM, colabora com programas de pós-graduação da UFAM, núcleos de estudos e pesquisas da UFAM, eventos científicos, projetos de extensão universitária e outras atividades acadêmicas. Email: suelyanm@ufam.edu.br

2 Professora DE, atuando na graduação e Pós-Graduação Universidade Federal do Amazonas. E-mail: fgarcia@ufam.edu.br

3 Professora DE, atuando na graduação e Pós-Graduação Universidade Federal do Pará. E-mail: vilmaaparecidadepinho@gmail.com

${ }^{4}$ Professor atuando na Pós-Graduação da Universidade De La Salle, Bajío, León, México. E-mail: 1solano@delasalle.edu.mx.
} 


\begin{abstract}
The human culture are millenial and it integrates the knowledge set and worldviews of human family. They integrate the identity of global citizens and its social subjectivity that impacts over the built of individual identity that guides th behavior in front of daily situations in both public and private lives. This article is part of a wide investigation supported by PROCAD/AMAZONIA, CAPES/UFAM/UFMT/UFPA (Protocol 8881.314288/2019-0), it aims to show representations of academic students from different countries (Brazil, México, Bolivia, Venezuela, Mozambique, Portugal, Spain, Dominican Republic and Colombia) about the appreciation of cultures from its territories. By international ethic procedure, participated $n=881$ academic students of both male and female gender. The instrument itself containing open and closed question was answered via internet with the support of invited researchers. The results shows perceptions of low valuation of original cultures from the academic students that impacts in discontentment between its members. Its concluded by the necessity of development of affirmative public policy to the inclusion of the study of original cultures in a effective way in general curriculum.
\end{abstract}

Keywords: Representation, original cultures, Academic Students, Schoolar Curriculum.

Este artigo, parte de uma investigação mais ampla realizada ao abrigo do PROCAD/AMAZONIA, CAPES/UFAM/UFMT/UFPA (Ref. Proc. 8881.314288/2019-0), objetiva apresentar representações de universitários de diferentes países (Brasil, México, Bolívia, Venezuela, Moçambique, Portugal, Espanha, República Dominicana e Colômbia) sobre a valorização das culturas de seus territórios (MASCARENHAS, 2019).

Com suas memórias roubadas, suas autênticas histórias ocultadas, os descendentes de civilizações originárias se tonam involuntariamente, cegos de si mesmos. Suas autênticas histórias são invisíveis pelo currículo injusto que lhes é imposto nas escolas dominadas pelas "elites" dirigentes dos estados racistas, classistas, subservientes dos imperialistas capitalistas selvagens. Sistema econômico e político que quer o ser humano para mão de obra simplesmente. Não havendo interessem em promover o desenvolvimento de suas capacidades e potencialidades individuais para realização pessoal (SEN, 2010). Por outro lado, constatamos que:

Nos deparamos com a urgência em desvelarmos os processos educativos que reforçam no cotidiano escolar o racismo que perpassa a invisibilidade da diferença por conta das subjetividades atingidas nesse processo de colonialismo que não reconhece a existência do outro -indígenas e negros como pessoas de culturas e sentimentos, de desejos e formas próprias de se reconhecer, de aprender e dar sentido ao viver coletivamente a partir de outros referenciais religiosos, familiares, comunitários e estéticos. A educação escolar, desde muito cedo, nega o corpo que se é, imobiliza, e nele inscreve a negação de sua identidade étnico racial, constituindo-o de negatividade pelo pensamento colonial (GRANDO,PINHO \& RODRIGUES, 2018, p. 86) 
As sociedades colonizadas em especial as da América Latina e África, são geralmente excludentes, classistas, racistas, colonialistas. Os sistemas educativos formais e informais têm um currículo oculto que reforça os valores e cosmovisão dos povos colonizadores excluindo as cosmovisões dos povos invadidos e colonizados, negando sua cultura, fragilizando sua identidade, escondendo sua história milenar e contribuição essencial para a construção dos atuais estados nacionais, estados que conservam características coloniais (BALLESTRIN, 20134)). Inclusive existe evidência em países como México, indicando que quanto maior tempo de escolarização, a identidade indígena e originária se vai negando para auto idenficar-se como mestiços (MARTÍNEX ET AL, 2014).

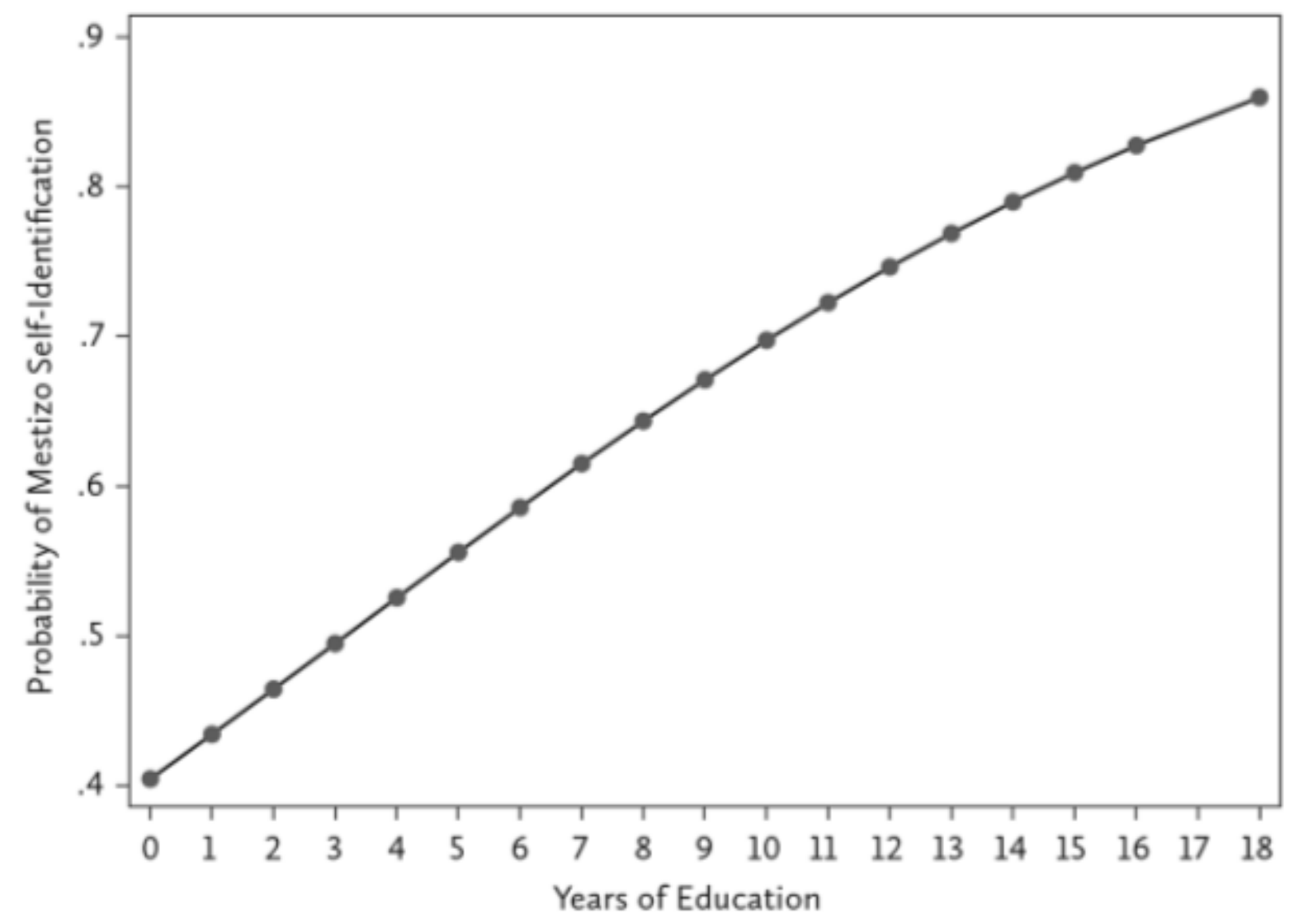

Fonte: Martínez, et al. 2014. Pág. 57

Sabemos que as culturas humanas são milenárias, integram o conjunto de saberes e cosmovisões da família humana. Integram a identidade dos povos e sua subjetividade social impactando sobre a construção da identidade individual que orienta o comportamento diante das situações cotidianas no âmbito público e privado. As escolas com seus currículos injustos, racistas, classistas e colonialistas lhes negam a história autêntica da humanidade da 
qual todos fazem parte. Um verdadeiro atentado ao bem comum o que se configura crime de lesa humanidade. Os povos africanos na África, os povos originários da América classificados como "índios" pelos colonizadores, os afrodescendentes na América e em todos os territórios colonizados, ao longo de séculos e inclusive na atualidade viviam e vivem em uma situação que os obriga a enfrentar o outro (brancos) e definir sua identidade vis a vis (frente a frente, tête à tête) desse outro que a negava e nega. Viveram por séculos e ainda vivem em países onde são marginalizados, discriminados e estigmatizados pela cor de suas peles e suas características fenótipas e culturais. Seus ancestrais viviam e atualmente os descendentes de "índios" e negros ainda vivem, apesar das vedações legais e constitucionais, em um ambiente social onde sua humanidade é negada (Ubuntu). Um ambiente que apesar das leis e constituições vigentes, na prática das relações interpessoais, em grande medida, o branco é sinônimo de força, de poder, de riqueza, de belo ... em detrimento do negro e do "índio" que são representados como ausência de luz, ausência de beleza, ausência de poder, ausência de civilização, pobreza (KAKOZI KASHINDI, 2012)

Em alguma medida utilizamos a filosofia africana Ubuntu para refletir e situar a condição de família humana em sentido amplo, nos apoiando nas perspectivas epistemológicas da complexidade e meta epistemologia de contexto, onde o histórico e o cultural são determinantes de nossa identidade e humanidade.

\footnotetext{
Ubuntu significa que ser um humano é afirmar sua humanidade por reconhecimento da humanidade de outros e, sobre estas bases, estabelecer relações humanas com os outros. Ubuntu, entendido como ser humano (humanidade); um humano, respeitável e de atitudes corteses para com outros constitui o significado principal deste aforismo. Ubu-ntu, então, não apenas descreve uma condição de ser, na medida em que é indissoluvelmente ligado ao umuntu, mas também é o reconhecimento do vir a ser e não, como desejamos enfatizar, o ser e o vir a ser. (RAMOSE, 1999, p.51)
}

O Ubuntu como filosofia africana Bantú, alude para a convivência para esse outro (outros seres humanos e outros seres). Viver com esse outro, respeitando-o em sua diferença e reconhecendo-o como valioso que é para minha existência, para minha vida. Me faz mais humano, já que me faz mais respeitoso, solidário, responsável, compassivo e generoso, não só para meus semelhantes, seres humanos, como para com a natureza. Isso é viver o Ubuntu, isso é ser humano (KAKOZI KASHINDI, 2012). Acreditamos que esta epistemologia é coerente com a condição de dignidade da vida humana em sociedade e precisa ser incorporada ao currículo escolar em geral. Como justiça curricular e valorização da alteridade humana. 
Somos todos originalmente humanos e em comunidades humanas que se desenvolveram igualmente ao longo dos séculos, construindo existências livres, soberanas que promoveram o bem comum para todos os seus membros. Todavia, desde a revolução industrial, os descendentes dos povos originários recebem uma educação para atender aos interesses do mercado de trabalho e terminam seu tempo sem conhecer sua história original autêntica, que impacta sobre sua identidade social e individual. Um mundo onde a justiça de dar a cada um o que lhe pertence deve assegurar, em primeiro lugar a verdade sobre a história que determina a identidade das pessoas. Esse é um desafio que os currículos escolares precisam enfrentar.

Vivir con ese otro, respetarlo en su diferencia y reconociendo lo valioso que es para mi existencia, para mi vida, me hace más humano, ya que me hace respetuoso, solidario, responsable, compasivo y generoso no sólo para con mis semejantes seres humanos, sino también con la naturaleza. Esto es vivir Ubuntu, esto es ser humano, (KAKOZI KASHINDI, 2012, p. 15).

A condição da soberania individual que caracteriza a essência de todos os seres humanos é compatível com a justiça que é dar a cada um o que lhe compete. A justiça que é uma condição ética da sociedade humana está sendo substituída por leis construídas por grupos imperialistas, colonialistas, classistas e racistas onde impera a lei do "mais forte" econômica e hegemonicamente. Situação histórica impele à resignação. Violando o que nos torna humanos: a liberdade, a criatividade, a soberania, o poder, a vontade. Não podemos ter um currículo que tenta nos tirar o que nos torna humanos. (Pensamos que nesse currículo atual que tenta desumanizar o ser humano, negar a dignidade de sua história, pode estar parte da causa para tantos problemas mentais, emocionais, depressão e suicídios em todas as camadas e idades. Ninguém merece um currículo que desvaloriza e torna invisível e marginal sua história e sua dignidade. O currículo atual é injusto por esconder a verdade histórica) (VILLAVICENCIO SANTILLÁN, 2016).

Os direitos conquistados ao longo dos últimos séculos com sangue, suor e lágrimas por nossos avós e pais estão sendo descartados. O que desumaniza a condição da vida humana em sentido amplo. Os "detentores do poder econômico" os "superpoderosos" se acham no direito de classificar e qualificar grupos, países, e tudo o que desejam classificar e qualificar. A quem servem? Essas agências mandam mais que governos democraticamente eleitos. Não há como debater ou dialogar com agências reguladoras e avaliadoras que não compartilham dos mesmos critérios que propagamos. Critérios de igualdade, dignidade, soberania, liberdade, vida em comunidade e bem comum. Critério de respeito à diversidade, unicidade e liberdade de criar, estudar, pesquisar e divulgar o pensamento e o conhecimento. (CASANOVA- 
GONAZÁLES, 2015). Como pessoas soberanas e livres, não precisamos da aprovação de outrem. Devemos seguir nossa essência e consciência humana, desenvolver nossas habilidades e capacidades únicas em prol do bem comum em nossos territórios e comunidades. Devemos satisfação à nossa própria consciência e auto aprovação. Somos únicos e não devemos imitar outros ou nos obrigarmos a seguir padrões que não respeitam nossa identidade, liberdade, unicidade, nossa humanidade, nossa alteridade. Esses aspectos em nossa perspectiva são aspectos a serem, oportunamente incluídos nos currículos escolares em geral. Cada pessoa para ser coerente consigo mesma e respeitar a diversidade cultural e humana da qual faz parte precisa passar por experiências de respeito e aceitação deste a primeira infância e ao longo de sua formação. Cada pessoa merece e tem direito ao respeito à sua unicidade. Os currículos, em nossa forma de avaliar não estão planejados para respeitar a diversidade cultural humana. Sendo um desafio da ciência da educação em sentido amplo.

Há que se recordar que a soberania é individual. A soberania política e dos governos é delegada a representantes livremente eleitos por cada soberano que integra a população de determinado território e país, ou seja: por cada pessoa em particular que habita o território. Não há que se observar leis ilegítimas que negam a história, a dignidade, a soberania, a liberdade, a criatividade das civilizações humanas. O que se caracteriza como uma indignidade inaceitável que faz com que as pessoas em geral fiquem indignadas por não terem sua dignidade respeitada, por não terem suas histórias e culturas presentes e valorizadas nos currículos escolares. (VILLAVICENCIO SANTILLÁN, 2016).

O currículo injusto que nega a verdade histórica das civilizações humanas, enaltecendo a cultura europeia em detrimento das diferentes culturas e civilizações humanas é inaceitável e precisa ser revisto, sob pena de roubar a história e prejudicar a identidade dos descendentes dos povos originários. Sem história, sem memória, cegos de si mesmos, invisíveis nos currículos das escolas colonialistas, imperialistas, classistas e racistas que dominam o sistema educativo em geral. (SILVA, 2018).

A diversidade humana é riqueza da humanidade. Essa verdade histórica demonstrada pelo patrimônio material e imaterial, os sítios arqueológicos em geral, merece ser ensinada, conhecida, apreciada, valorizada. Cada pessoa tem direito de ouvir de seus professores, desde o primeiro dia de aula que é descendente das civilizações ancestrais e que tem um potencial único importante para o bem da humanidade. Com esse currículo justo a escola estará colaborando para desenvolver as capacidades e potencialidades dos estudantes em geral, de modo que venham a realizar seus projetos de vida favorecendo o bem comum da humanidade e o seu bem estar e realização pessoal. 
Pode ser utópico diante dos fatos do currículo atual colonizado, esvaziado de sentido para os descendentes dos povos originários em geral. Para que serve a utopia? A utopia é como o horizonte. Quanto mais nos aproximamos do horizonte, mais o horizonte se afasta. A utopia serve para caminharmos, para avançarmos em direção aos novos paradigmas de fortalecimento da igualdade humana. A justiça e a liberdade são irmãs da soberania e dignidade da pessoa humana. Essas informações precisam estar no currículo justo das escolas em todas as esferas (da educação infantil à pós-graduação).

O sistema escolar formal como um dos aparelhos ideológicos do Estado, controla os conteúdos curriculares que são ensinados aos estudantes em geral durante os cursos escolares. Tais conteúdos em grande medida servem para favorecer a construção da identidade social e pessoal em sentido amplo. Uma vez que a identidade é enraizada na história social e individual e da memória coletiva. Um currículo conservador que não permite às novas gerações conhecer a história da formação de seus povos e nações é antes de tudo injusto, colonialista, imperialista, classista, racista e indigno de ser aplicado. Esse currículo injusto praticado na maioria das escolas, que impacta sobre a formação da identidade nacional, social e individual de forma extremamente desfavorável para o bem estar psicossocial e individual dos estudantes. (O’SHEA, 2018).

Como seres humanos não podemos abrir mão ou prescindir das características que nos tornam humanos: a soberania individual, a unicidade individual, a liberdade individual, a criatividade individual, o poder individual, o livre arbítrio individual dentre outras características pessoais. Tais características são peculiares à condição humana sem as quais empobrecemos nossa humanidade e até podemos adoecer e morrer.

O sistema escolar em geral, do ponto de vista formal, tem como objetivo promover o desenvolvimento das capacidades e potencialidades humanas, preparar as pessoas desde a infância até a idade adulta para o exercício consciente, participativo e interventivo da cidadania e o trabalho. Todavia, os indicadores atuais revelam espaços escolares violentos, com baixos indicadores de aprendizagem e desenvolvimento humano, liberdade e soberania (SEN, 2010).

São espaços que possuem um currículo desconectado dos interesses individuais e focados no desenvolvimento tecnológico, e nos interesses do mercado. O que, em grande medida, não coincide com os interesses de desenvolvimento pessoal dos estudantes, visto que desconsidera suas características e interesses individuais. Daí os elevados índices de desistência escolar, reprovação escolar e outros fenômenos que em conjunto são conhecidos com "fracasso escolar". 
Temos uma escola formal eurocêntrica, colonizadora, imperialista, classista e racista que ignora a riqueza cultural e a sociodiversidade que caracteriza os povos dos territórios colonizados. O que impacta sobre os indicadores de bem viver e satisfação com a vida dos estudantes uma vez que não percebem em suas escolas a presença de suas culturas ancestrais originárias, sendo forçados a estudar somente as culturas dos povos colonizadores que invadiram e pilharam seus territórios, impondo seus costumes, religião, língua, alimentação, vestuário, festividades, silenciando e marginalizando as culturas e tradições dos povos dos territórios colonizados. (VILLAVICENCIO SANTILLÁN, 2016).

Os descendentes dos milenários povos colonizados que percebem a ausência de suas culturas e histórias nas histórias registradas nos livros escolares em geral sentem uma grande tristeza emocional pois seus ancestrais e sua história são ignoradas, silenciados, marginalizados. Daí o currículo escolar injusto pois não dá a cada um o que lhe pertence: o direito à verdade, à sua história ancestral. (SILVA, 2018).

O currículo escolar em geral, ao negar a história dos povos originários tanto dos apelidados como" índios" por Cristóvão Colombo e pelos colonizadores em geral, como no caso do Brasil, os seres humanos que foram sequestrados do continente africano para trabalhar como escravizados em territórios da Europa e América, lhes nega a História milenar ancestral, a memória, a identidade. São tratados como escravizados, mão de obra barata para toda obra. Não são tratados como seres humanos. Daí ser um currículo injusto e desumanizador de lesa humanidade. (VILLAVICENCIO SANTILLÁN, 2016)

Mesmo porque as atuais elites dos países colonizados, em grande medida, são constituídas por descendentes de colonizadores portugueses e espanhóis que vieram para enriquecer financeira e economicamente nestes territórios, e resistem em reconhecer as culturas e civilizações originárias em sua importância e dignidade humana. Daí o mal-estar social onde grande parcela da sociedade não se percebe nos currículos escolares, o que impacta negativamente sobre sua identidade e bem viver na sociedade onde se inserem, são como estrangeiros em seu próprio território ancestral (TRUEBA, 2012).

Os tributos pagos pelos países do "terceiro mundo", na forma de dívida financeira externa assemelham-se aos tributos pagos por povos colonizados a suas metrópoles e pelos países subjugados aos impérios. Podendo ser considerado uma forma de colonização e exploração histórica, daí a reflexão entre independência formal x independência de fato, e por outro lado a afirmação de que os países lograram de fato a independência de "hino e bandeira", uma vez que a vontade soberana dos povos dominados economicamente e oprimidos culturalmente, silenciados em sua identidade ancestral não é respeitada, pelo 
contrário é totalmente ignorada em grande medida pelos Estados que administram as diferentes nações. No caso da Amazônia brasileira e das regiões do interior dos países, podemos falar de colonialismo interno, onde as regiões mais industrializadas exploram as matérias primas das regiões menos industrializadas, reduzindo o volume financeiro para apoiar os investimentos em infraestrutura e qualidade de vida das regiões exportadoras de matéria prima, que apresentam indicadores menos favoráveis de bem viver, em comparação com os indicadores das regiões mais industrializadas. Daí o colonialismo interno. Fenômeno que em uma pátria, uma família nacional (nação), precisa ser discutido e superado para que todos os membros da família nacional usufruam dos recursos pátrios de forma igualitária. Que sejam superadas as desigualdades regionais entre os países em geral. (CASANOVAGONAZÁLES, 2015)

Seres humanos por sua condição e dignidade merecem respeito. O processo político e econômico da colonização que se enraíza na cosmovisão de que todos os seres são como coisas a serem exploradas não é coerente com a condição humana em sentido amplo. (VILLEGAS, 2019).

O sistema escolar em todas as esferas, desde a educação infantil à pós-graduação atua como ente colonial e econômico que atua ao serviço do desenvolvimento tecnológico, em prol do crescimento financeiro, o que, em grande medida, contribui para a precarização da vida humana, não promovendo o desenvolvimento das capacidades e potencialidades individuais tendo em vista a auto realização e o bem comum. Entendemos que tal realidade não pode prevalecer nem prosperar, sob pena de desumanizar o ser humano, negando sua dignidade, liberdade, soberania e poder (GROSFOGUEL, 2016). Os currículos escolares devem aportar o questionamento das relações de poder, ao mundo das interações cotidiana e sobretudo com as formas em que as diferenças são processadas a partir de paradigmas de dominação cultural (VICH, 2014. Pág. 49).

Embora com suas independências de "Hino e Bandeira" promulgadas há séculos, grande parte do Estados latino americanos e africanos continuam a sobreviver como Estados colonizados por governos manobrados por interesses econômicos financeiros transnacionais. O processo de extrativismo selvagem e o desrespeito aos territórios e soberania das civilizações invadidas e saqueadas desde o século $\mathrm{XV}$, revelam interseções entre o processo contínuo de degradação ambiental, exploração capitalista selvagem nos territórios onde estão instaladas empresas multinacionais que não respeitam direitos trabalhistas locais e legislação ambiental. (RODNEY, 1981). Tal Realidade demonstra que o colonialismo está longe de ser considerado um antecedente histórico para a vida econômica e política de grande parte dos 
territórios atualmente nomeados de "América Latina". América latina onde são faladas centenas de línguas das civilizações originárias... certamente no futuro essa denominação será modificada. Por enquanto, sabermos que o colonialismo externo e interno é um aspecto que define as diversas formações políticas na região. (CASANOVA-GONAZÁLES, 2015).

O fenômeno econômico e político do colonialismo envolve o roubo de terras dos habitantes que integram as civilizações originárias dos territórios invadidos, por um lado, e por outro, a transferência ou migração forçada dessas populações que alijados de seus territórios com suas riquezas originais, sua cultura e modos de produção promove o truculento processo histórico e político de empobrecimento material de seus descendentes. O processo colonizador classifica tudo como "recursos", entes econômicos acima de tudo (terra, riquezas naturais, pessoas para trabalho quase escravizado). O fenômeno da colonização entende que o mundo físico e todos os seres, inclusive o humano são recursos econômicos (TUCK E YANG, 2012). A exploração do trabalho nos estabelecimentos escolares neoliberais, da educação infantil à pós-graduação revela um modelo econômico colonial, uma vez que trata as pessoas como insumos e não como seres humanos livres, com vontade soberana, poder e dignidade que se realizam pelo trabalho como uma criação humana individual embora desenvolvida de modo inter-relacionado com o coletivo onde se insere.

O desafio da construção de um currículo intercultural que valorize as expressões culturais da humanidade como um todo é urgente e em nossa perspectiva de análise precisa ser implementado de imediato. Os novos currículos incluirão uma lógica que formem pessoas integrais com uma visão holística. Por outro lado, que contemple processos que harmonizem as competências de caráter intelectual, social, biopsicossocial e trabalho orientado ao compromisso de formar não para lógicas laborais, para impor uma lógica social que esteja determinada pela aplicação dos saberes ancestrais, e que adotem o compromisso de incorporar elementos próprios e contextualizados ao currículo e que se articulem com saberes ancestrais que incluam práticas pedagógica e andragógicas. Esse é um desafio a ser superado, pois na atualidade, a estrutura colonizada dos currículos eurocêntricos é incompatível com a busca e o fortalecimento da identidade educativa dos países. (VILLAVICENCIO SANTILLÁN, 2016).

Nesta pesquisa com dimensões mais amplas, apoiada na perspectiva da epistemologia de contexto e complexidade busca avançar na construção de novos conhecimentos cientificamente sistematizados que demonstrem o impacto de aspectos históricos sobre a identidade, o rendimento e o bem estar dos participantes. Os participantes são universitários (estudantes, docentes e técnicos) de diferentes universidades e países (MASCARENHAS, 2019). 
A perspectiva da pesquisa apoia-se na visão de que a alteridade é constitutiva do profundamente humano, motivo pelo qual sua valorização é essencial nos currículos em geral como forma de reconhecer a dignidade e soberania da condição humana em geral. O currículo não colonizado, não eurocêntrico em nossa perspectiva teria em seu núcleo o princípio de que cada ser humano expressa sua humanidade e unicidade em relação aos outros membros a humanidade desenvolvendo suas habilidades e capacidades, sua unicidade em prol do bem como. Com dignidade e liberdade, com uma importância essencial para si e para a comunidade o que, em nossa perspectiva, irá impactar na formação de identidades mais autônomas e saudáveis que poderão contribuir positivamente para o desenvolvimento social e o bem comum, (CASTRO 2001).

\section{O CONTEXTO DA PESQUISA}

$\mathrm{Na}$ primeira fase da investigação longitudinal participaram 29 instituições de ensino superior. Sendo: Universidade Federal do Amazonas, UFAM, Brasil com n=70, 7,9\%; Universidade Federal de Rondônia/UNIR-Brasil, n=45, 5,1\%; Universidade Federal de Mato Grosso/UFMT-Brasil, n=19,2,2\%; Universidade Federal do Oeste do Pará/UFOPA-Brasil, n=27, 3,1\%; Universidade Federal de Pernambuco/UFPE-Brasil, n= 47, 5,3\%;Universidade La Salle, Manaus - Brasil, n=45, 5,1\%; Universidade Nacional Autónoma de México/UNAM - México, $\mathrm{n}=385,43,7 \%$; Universidade La Coruña/UDC - Espanha, $\mathrm{n}=10,1,1 \%$; Universidade Pedagógica Nacional/UNP- México, n= 26, 3,0\%;Universidad Externado de Colômbia, Colômbia, n=2, 0,2\%; Universidad de La Amazônia Boliviana - UNAB, Bolívia, n=1, 01\%; Universidad Gabriel René Moreno, Santa Cruz de La Sierra, Bolívia, n=29, 3,3\%, Universidad Pedagógica Externado Libertador, UPEL, Venezuela, $\mathrm{n}=35,4,0 \%$; Universidad do Algarve, Faro, Portugal, n=2, 0,2\%; Universidade Pedagógica de Moçambique, n=39, 4,4\%; Universidade de Licurgo, Moçambique, $\mathrm{n}=16,1,8 \%$; Universidade Federal de São Paulo, Brasil, $\mathrm{n}=1,0,1 \%$; Universidade de Aveiro, Aveiro, Portugal, $\mathrm{n}=1,0,1 \%$; Universidade de Lisboa, Portugal, $\mathrm{n}=1,0,1 \%$; Universidade do Porto, Portugal, $\mathrm{n}=1,0,1 \%$; Uninorte, Manaus, Brasil, $n=1,0,1 \%$; Universidade Nilton Lins, Manaus n=2, 0,2\%; UEM, Moçambique, $\mathrm{n}=1,01, \%$; Universidade Federal de Minas Gerais, Brasil, $\mathrm{n}=1,0,1 \%$; Universidade Federal do Pará, $\mathrm{n}=14,1,6 \%$; Universidade Pedagógica de Maputo, Moçambique, $\mathrm{n}=8,0,9 \%$, Universidad Frederico Henriques y Carvajal, República Dominicana, $\mathrm{n}=58,5,4 \%$; UNISAVE, Brasil, $\mathrm{n}=2,0,2 \%$; Instituto Superior de Psicologia Aplicada - ISPA, Portugal, n=2, 0,2\%. 


\section{PARTICIPANTES DA PESQUISA}

Participaram desta fase da investigação $n=881$ pessoas. Sendo $n=271,30,8 \%$ do Brasil, $\mathrm{n}=409,46,4 \%$ do México, $\mathrm{n}=11,1,2 \%$ da Espanha, $\mathrm{n}=7,0,8 \%$ de Portugal, $\mathrm{n}=67$, 7,6\% de Moçambique, $n=30,3,4 \%$ da Bolívia, $n=2,02 \%$ da Colômbia, $n=34,3,9 \%$ da Venezuela, $n=48,5,4 \%$ da República Dominicana e $n=2,02 \%$ de outros países. Quanto ao estado civil dos participantes, $n=586,66,5 \%$ são solteiros; $n=177$ são casados/as, $20,1 \%$; $n=78$ vivem em união estável $8,9 \%$. $\mathrm{N}=36,4,1 \%$ são divorciados e $\mathrm{n}=4,0,5 \%$ são viúvos

Entendemos que essa variável histórica exerce impacto importante sobre a subjetividade social das sociedades alvo do processo de colonização que impactou sobre as culturas, a auto- estima e o auto conceito das sociedades envolvidas. Acreditamos que se faz necessário ampliar o diálogo sobre esse fenômeno histórico, econômico e político da colonização e seus impactos sobre o bem estar das sociedades envolvidas.

Dentre os participantes $n=599$ são do sexo feminino $63,5 \%$ e $n=322$ do sexo masculino 36,5\%. Idades entre 18 e 70 anos, $\underline{M}=30,6 ; \underline{\mathrm{DP}}=12,17$. Das instituições de ensino superior participantes nesta fase da investigação, registramos que $\mathrm{n}=788,88,3 \%$ dos participantes são vinculados a instituições públicas e $n=103,11,7 \%$ a instituições particulares. Destes estão vinculados à modalidade presencial $n=699,79,3 \%, n=11,1,2 \%$, participantes à modalidade semi-presencial e $n=171,19,4 \%$ à EAD. No que se refere à categoria de participantes da investigação registramos nesta primeira fase $n=711$ estudantes, 80,7\%; $n=106$ docentes, $12,0 \%$ e n=64 técnicos, 7,3\%.

No que se refere à identidade étnica, $n=175$ dos participantes identificam-se como brancos 19,9\%; $\mathrm{n}=111$ como negros, $12,6 \%, \mathrm{n}=554$ como mestiço/pardo 62,8\% e $\mathrm{n}=42,4,8 \%$, como integrantes dos povos primeiros no território, classificados pelos Estados e nações colonizadoras e imperialistas em geral como "indígenas" em função da forma como Colombo os denominou em 1492, por pensar que teria encontrado uma nova rota para as índias. Entendemos que esse segmento da sociedade integra civilizações primeiras que habitavam o território antes da invasão de civilizações do velho mundo (Europa, Oriente Médio e Ásia) para colonizar e explorar os territórios em causa.

Os resultados demonstram percepção de baixa valorização das culturas originárias por parte dos universitários impactando em descontentamento entre os integrantes dessas culturas. Concluímos pela necessidade da criação de políticas públicas afirmativas para inclusão do estudo das culturas originárias de maneira efetiva nos currículos em geral com forma de estabelecer justiça curricular para todos. 
Quadro 1: Representações ¿Sabe cuántas culturas originarias hay en el país en donde vive? Universitários, 2019

\begin{tabular}{|c|c|c|c|}
\hline España & Femenino & 20 & $\begin{array}{l}\text { En la escuela muchas veces se limitan a informar sobre la } \\
\text { cultura o la historia de la gran mayoría, dejando relegadas a un } \\
\text { segundo plano otras más minoritarias, pero no por ello menos } \\
\text { importantes. }\end{array}$ \\
\hline \multirow[t]{2}{*}{ México } & Femenino & 20 & $\begin{array}{l}\text { La información sobre las culturas originarias en México es } \\
\text { infravalorada }\end{array}$ \\
\hline & Masculino & 69 & $\begin{array}{l}\text { El gobierno, siempre las ha despojado y aniquilado aliado con } \\
\qquad \text { los dueños del dinero (FMI, BID, FAO, etc) }\end{array}$ \\
\hline México & Femenino & 63 & Cuando yo estudié la primaria sí veíamos textos de esos \\
\hline México & Masculino & 49 & $\begin{array}{l}\text { Es tal la variedad de pueblos indígenas en México que sería } \\
\text { muy difícil abarcarlas todas. }\end{array}$ \\
\hline México & Masculino & 48 & Se estudia muy general. \\
\hline México & Femenino & 24 & $\begin{array}{l}\text { No se les da interés, prefieren concoer otras culturas quer la } \\
\text { propia, repito, influencia española. }\end{array}$ \\
\hline México & Femenino & 57 & $\begin{array}{c}\text { Aquí el gobierno los ha hecho parte del atractivo histórico para } \\
\text { incrementar el turismo a través del programa de Pueblos } \\
\text { Mágicos }\end{array}$ \\
\hline México & Masculino & 25 & $\begin{array}{l}\text { Muy poco, pero se nos enseña más a respetar y a alabar al } \\
\text { colonizador, muy sadomasoquista, diría Dussel }\end{array}$ \\
\hline México & Femenino & 55 & $\begin{array}{l}\text { Falta cultura de pueblos originarios su carácter y de las mezclas } \\
\qquad \text { que surgieron. }\end{array}$ \\
\hline México & Masculino & 41 & $\begin{array}{l}\text { se conocen de manera superficial y al final existen libros que } \\
\text { refieren historias diferentes a lo que se enseña en las escuelas. }\end{array}$ \\
\hline México & Femenino & 53 & $\begin{array}{l}\text { En una comunidad tienen una estación de radio en su lengua } \\
\qquad \text { nativa (hñahñú). }\end{array}$ \\
\hline México & Femenino & 37 & Solo las más representativas \\
\hline México & Femenino & 47 & $\begin{array}{l}\text { Algunas de ellas, son estudiadas, e inclusive se están tratando } \\
\text { de preservar los aspectos culturales principales, como son la } \\
\text { lengua y las costumbres }\end{array}$ \\
\hline México & Femenino & 19 & $\begin{array}{l}\text { Se estudia su historia, pero la mayor parte de la población } \\
\text { ignora mucho de dicha historia de las culturas originarias de } \\
\text { México. }\end{array}$ \\
\hline México & Femenino & 55 & Se han realizado esfuerzos pero no han sido suficientes \\
\hline México & Masculino & 53 & $\begin{array}{l}\text { Son muchas las culturas originarias en México. Algunas son } \\
\text { estudiadas, las más protagónicas y grandes. Hay muchas } \\
\text { culturas originarias pequeñas en regiones distantes. }\end{array}$ \\
\hline
\end{tabular}




\begin{tabular}{|c|c|c|c|}
\hline México & Masculino & 33 & $\begin{array}{l}\text { Solo como ejemplos de de grandeza a través de los vestigios } \\
\text { arquitectónicos, y actividades culturales, la vida diaria de las } \\
\text { culturas originarias se caracteriza por la pobreza y desigualdad }\end{array}$ \\
\hline México & Masculino & 57 & $\begin{array}{l}\text { No, porque existe aún el paradigma de la estigmatización en } \\
\text { todos los aspectos de las etnias a nivel nacional. }\end{array}$ \\
\hline México & Masculino & 18 & $\begin{array}{l}\text { Cosas como el día de muertos, algunos dioses, cultura general, } \\
\text { pero nada serio. }\end{array}$ \\
\hline México & Femenino & 20 & $\begin{array}{l}\text { Por supuesto que no. Solo se estudian a los grupos que fueron } \\
\text { más influyentes y aún así, la mayoría de los mexicanos no sabe } \\
\text { mucho al respecto. }\end{array}$ \\
\hline México & Femenino & 31 & $\begin{array}{l}\text { Se llega a tocar el tema en ciertas clases a diferentes niveles } \\
\text { educativos pero no son profundizados estos temas y son } \\
\text { olvidados con el tiempo. No se le da la importancia que } \\
\text { merecen }\end{array}$ \\
\hline México & Masculino & 24 & $\begin{array}{l}\text { Gran importancia de la educación se basa en la historia de } \\
\text { México que se da desde la primaria. }\end{array}$ \\
\hline México & Femenino & 53 & Debería hacerse \\
\hline México & Femenino & 19 & Pienso que tal vez, solo algunas \\
\hline México & Femenino & 40 & $\begin{array}{l}\text { Existen grupos étnicos y lenguas nativas, pero en las escuelas } \\
\text { sólo se mencionan, mas no se estudian. Más bien se enseña el } \\
\text { español, como resultado de la colonización y las costumbres o } \\
\text { tradiciones nativas, no se toman en cuenta, sólo existen escuelas } \\
\text { laicas o religiosas. }\end{array}$ \\
\hline México & Femenino & 62 & $\begin{array}{l}\text { Si son estudiadas y no son conocidas por la mayoría de la } \\
\text { población }\end{array}$ \\
\hline México & Femenino & 40 & Sólo hay escuela laica o religiosa no hay sobre grupos étnicos \\
\hline México & Femenino & 29 & $\begin{array}{l}\text { Considero que sí, al menos cuando estudié la educación básica } \\
\text { y media superior tuve excelentes maestros y programas que me } \\
\text { permitieron conocer varias culturas y la historia de nuestro país }\end{array}$ \\
\hline México & Femenino & 38 & $\begin{array}{l}\text { para los que estudiamos carreras de humanidades y ciencias } \\
\text { sociales }\end{array}$ \\
\hline México & Femenino & 56 & Lo cual lamento pues las historias, o leyendas no se difunden. \\
\hline México & Femenino & 45 & $\begin{array}{l}\text { Se revisan algunas historias de los pueblos originarios, pero de } \\
\text { manera general, con adaptaciones, al ser interpretadas y } \\
\text { traducidas pierden ciertas características, por ejemplo, al } \\
\text { traducir una leyenda o mito de la lengua original al español, en } \\
\text { el momento de hacer la traducción pudiera ser que se pierda la } \\
\text { intención de la idea que se quiere trasmitir, entonces ya no se } \\
\text { estudia desde el punto de vista original, sino de la perspectiva } \\
\text { de quien lo esta estudiando, y si en ese momento quien lo esta }\end{array}$ \\
\hline
\end{tabular}




\begin{tabular}{|c|c|c|c|}
\hline & & & $\begin{array}{c}\text { estudiando tiene una perspectiva distinta de la original, le va a } \\
\text { dar una interpretación distinta y quizá así sea trasmitida } \\
\text { subsecuentemente. }\end{array}$ \\
\hline México & Femenino & 33 & $\begin{array}{l}\text { Vivo en Quintana Roo, la cultura Maya es fuerte, los Maya } \\
\text { hablantes son muchos y hasta cierto punto la explotación } \\
\text { comercial de la zona utiliza la cultura para explotarla, logrando } \\
\text { visibilizarla }\end{array}$ \\
\hline México & Femenino & 33 & $\begin{array}{l}\text { En ocasiones se conocen sus nombres pero no se valora a las } \\
\text { personas pertenecientes a ellas y sobre todo en las ciudades son } \\
\text { vistos y tratados como personas que no pertenecen a eso, a } \\
\text { ciudades. }\end{array}$ \\
\hline México & Femenino & 47 & No se estudian de manera formal, es autodidacta. \\
\hline México & Femenino & 29 & Creo que no se le da el valor debido \\
\hline México & Femenino & 53 & No se les considera en ningún sentido. \\
\hline México & Femenino & 43 & $\begin{array}{l}\text { Una embarrada, lo que sé, es porque aprendí a conocer la } \\
\text { historia de mi país. }\end{array}$ \\
\hline México & Masculino & 24 & $\begin{array}{l}\text { Solo la cultura azteca y maya son estudiadas medianamente a } \\
\text { profundidad, de hecho las lenguas nativas se pierden progresiva } \\
\text { e irremediablemente. las demás solo pocos párrafos en los } \\
\text { textos y la información es errónea y manipulada }\end{array}$ \\
\hline México & Femenino & 24 & $\begin{array}{l}\text { Las mencionan durante las clases normalmente de educación } \\
\text { básica pero solo de una forma de conteo histórico, sin darle la } \\
\text { importancia de recuperación y revalorización }\end{array}$ \\
\hline México & Femenino & 25 & $\begin{array}{c}\text { Se conoce la historia prehispánica, pero no se desglosa como tal } \\
\text { todas las comunidades que hay y su historia }\end{array}$ \\
\hline México & Femenino & 42 & $\mathrm{Si}$, porque las aprendí en la primaria \\
\hline México & Masculino & 46 & $\begin{array}{l}\text { Siempre tratan de hasta cambiar la historia y nadie hace nada } \\
\text { para recuperar los hechos reales, no los oficiales. }\end{array}$ \\
\hline México & Masculino & 20 & $\begin{array}{l}\text { Las culturas más grandes son las más comentadas a lo largo de } \\
\text { la preparación académica }\end{array}$ \\
\hline México & Femenino & 52 & Son diversas y variadas y poco conocidas \\
\hline México & Masculino & 52 & $\begin{array}{l}\text { en mi época primaria y secundaria muy poco, desconozco los } \\
\text { nuevos contenidos }\end{array}$ \\
\hline México & Masculino & 22 & $\begin{array}{l}\text { Solo de los Mexicas y Mayas, las demás aún no se meten al } \\
\text { consciente colectivo }\end{array}$ \\
\hline México & Femenino & 31 & $\begin{array}{l}\text { Antes en historia de México incluían el estudio de las culturas: } \\
\text { maya, olmeca, azteca, etcétera, pero con los nuevos modelos } \\
\text { educativos ya no aparecen esas temáticas }\end{array}$ \\
\hline México & Femenino & 26 & $\begin{array}{l}\text { Muchas veces en las escuelas conocen más de la historia } \\
\text { mundial que de la historia nacional y local }\end{array}$ \\
\hline
\end{tabular}




\begin{tabular}{|c|c|c|c|}
\hline México & Femenino & 26 & $\begin{array}{l}\text { muchas veces las tradiciones de mi país han sido suprimidas } \\
\text { dentro del currículo nulo }\end{array}$ \\
\hline México & Femenino & 21 & si ya que se enseña en educación básica \\
\hline \multirow[t]{2}{*}{ Bolivia } & Femenino & 27 & No son estudiadas todas, solo tres o cuatro \\
\hline & Femenino & 24 & $\begin{array}{c}\text { No todos los colegios eñsenan las lengajes nativos del país. } \\
\text { Seria excelente que todos los colegios enseñarán los principales } \\
\text { quechua, aymara, guaraní. . }\end{array}$ \\
\hline México & Femenino & 45 & $\begin{array}{l}\text { Considero que las estudiamos como algo del pasado, sin } \\
\text { reconocer que aún están presentes con distorsionados vestigios } \\
\text { pero lo están }\end{array}$ \\
\hline México & Masculino & 53 & $\begin{array}{l}\text { No existe un interés por parte de las autoridades en difundir } \\
\text { nuestra auténtica historia. }\end{array}$ \\
\hline México & Femenino & 22 & Sólo las más representativas de la historia de México. \\
\hline Venezuela & Femenino & 24 & $\begin{array}{l}\text { Se ha establecido muchas veces un grado de inclinación por } \\
\text { conocer y descubrir más sobre cierta cultura que otra, quitando } \\
\text { el mérito de las demás. Aunque a nivel educativo se ha tratado } \\
\text { de implementar el conocimiento de las civilización con mayor } \\
\text { representación nacional. }\end{array}$ \\
\hline México & Femenino & 53 & Es un área del estudio de la Historia que no se ha considerado \\
\hline México & Femenino & 23 & Somos enseñados desde la primaria como pueblo colonizado \\
\hline México & Femenino & 22 & $\begin{array}{l}\text { Se revisan algunas cosas en la primaria y secundaria pero no } \\
\text { todas las historias son verídicas }\end{array}$ \\
\hline México & Femenino & 22 & $\begin{array}{l}\text { Nos enseñan únicamente la historia de lo conquistadores, de } \\
\text { Europa y una pequeña parte es sobre los pueblos nativos, pero a } \\
\text { partir del periodo de la conquista se pierden en la historia. }\end{array}$ \\
\hline México & Masculino & 21 & A ciencia cierta, no lo se \\
\hline México & Femenino & 23 & No siempre es así. \\
\hline México & Femenino & 20 & Solo importa el país, no las comunidades \\
\hline $\begin{array}{c}\text { Rep. } \\
\text { Dominicana }\end{array}$ & Masculino & 24 & $\begin{array}{l}\text { Va no se habla de la historia pasada las nuevas modalidades han } \\
\text { cambiado todo el esquema. }\end{array}$ \\
\hline México & Femenino & 21 & Son memorizadas, por lo mismo se olvidan. \\
\hline
\end{tabular}

Fonte: Base dados LAPESAM/UFAM/CNPq, 2019.

Da análise das representações das expressões registradas no quadro 1, constatamos que em grande medida, os participantes não percebem que os currículos escolares e a sociedade em geral valorizam as culturas e "nossa autêntica história" dos povos não europeus.

O conjunto de representações dos participantes de língua espanhola demonstra que o sistema escolar ainda não promove a inclusão da história dos povos em geral de modo a 
valorizar a contribuição do conjunto da sociedade para o avanço e o bem estar da humanidade. Destacamos as seguintes representações: (i) "Somos enseñados desde la primaria como pueblo colonizado"; (ii) "Nos enseñan únicamente la historia de los conquistadores, de Europa y una pequeña parte es sobre los pueblos nativos, pero a partir del periodo de la conquista se pierden en la historia", (iii) "No todos los colegios eñsenan las lengajes nativos del país. Seria excelente que todos los colegios enseñarán los principales quechua, aymara, guaraní", (iv) "Antes en historia de México incluían el estudio de las culturas: maya, olmeca, azteca, etcétera, pero con los nuevos modelos educativos ya no aparecen esas temáticas" e (v) "Solo la cultura azteca y maya son estudiadas medianamente a profundidad, de hecho las lenguas nativas se pierden progresiva e irremediablemente. Las demás solo pocos párrafos en los textos y la información es errónea y manipulada”. Para o caso de México, este resultado é esperado pois, fazendo memória e com a incorporação à globalização nos anos 1990, a educação ia modificando, e girando a uma "modernidade", onde a qualidade que tem maior atenção nos livros de textos oficiais é identificar-se como mestiços (CORONA, 2015). O que demonstra que os universitários reconhecem a baixa presença das histórias e culturas das civilizações nos currículos escolares. O que que configura como injustiça curricular por negar o acesso à verdade histórica dos ancestrais (Quadro 1).

Esse inseguro mundo onde a liberdade, a soberania, o poder e a criatividade humana são ameaçados pela educação a serviço quase que exclusivamente dos avanços tecnológicos a serviço do lucro, tem colocado em risco a vida humana no planeta. A identidade histórica não pode ser negada, a história é elemento constituinte de nossa identidade. Se nos negam a história danam nossa identidade. É urgente a construção de um currículo escolar justo que inclua todos os saberes das civilizações humanas de forma equilibrada.

Quadro 2: Na sua percepção, as civilizações que tiveram seu território colonizado na atualidade têm sua cultura valorizada como uma importante contribuição para a família humana? Universitários, 2019

\begin{tabular}{|l|l|l|l|}
\hline Brasil & Femenino & $\mathbf{5 3}$ & Na grande maioria são marginalizados e silenciados \\
\hline Brasil & Femenino & $\mathbf{4 8}$ & $\begin{array}{l}\text { Sim, pois a cultura é que nos faz perceber o quanto somos } \\
\text { diferentes e que precisamos através desta aprender com as } \\
\text { diferenças. }\end{array}$ \\
\hline Brasil & Femenino & $\mathbf{4 8}$ & Nova era Bolsonaro - retrocesso total \\
\hline Brasil & Masculino & $\mathbf{4 9}$ & $\begin{array}{l}\text { Não há programas efetivos, nas escolas, por exemplo, que } \\
\text { valorize a cultura de nossos antepassados. }\end{array}$ \\
\hline Brasil & Feminino & $\mathbf{4 9}$ & $\begin{array}{l}\text { Não, porque por exemplo o nosso país foi colonizado e não } \\
\text { temos as culturas da diversidade valorizadas como uma }\end{array}$ \\
\hline
\end{tabular}




\begin{tabular}{|l|l|l|l|}
\hline & & & importante contribuição para a família humana. \\
\hline Brasil & Masculino & $\mathbf{5 1}$ & Pouca ou nada de valorização \\
\hline
\end{tabular}

Fonte: Base dados LAPESAM/UFAM/CNPq

Da análise das representações apresentadas por universitários da língua portuguesa, constata-se que a percepção é de pouca valorização das culturas das civilizações locais pelo currículo escolar, dentre outras destacamos: (i) "Não há programas efetivos, nas escolas, por exemplo, que valorize a cultura de nossos antepassados"; (ii) "Não, porque por exemplo o nosso país foi colonizado e não temos as culturas da diversidade valorizadas como uma importante contribuição para a família humana" e “ (iii) "Na grande maioria são marginalizados e silenciados" (Quadro 2).

O que demonstra que após dezenas de anos de escolarização as lideranças acadêmicas não desenvolveram conhecimentos associados aos saberes interculturais de seus ancestrais. $\mathrm{O}$ que em nossa ótica se traduz com um dano de lesa humanidade.

Daí o desafio que as lideranças acadêmicas possuem de reformular os currículos da educação escolar incluindo os saberes das civilizações em geral de modo a incluir os conhecimentos construídos historicamente pela humanidade que podem impactar na melhoria das relações interpessoais e bem comum de todos os seres humanos, de modo a assegurar um currículo justo (SILVA, 2018).

\section{CONCLUSÃO}

Com as informações aportadas pela pesquisa, é possível afirmar que os universitários em grande medida entendem que a valorização das culturas em geral não é uma realidade nos currículos da educação escolar. O que demonstra um currículo colonizado que não serve aos princípios de valorização do legado de todas as civilizações negando a justiça curricular. $\mathrm{O}$ que pode ser explicado pelo imperialismo articulado que domina o sistema capitalista selvagem na atualidade. Demonstramos que o currículo colonizado que rege as dinâmicas escolares em todas as esferas do processo de ensino-estudo-aprendizagem, na realidade escolar que vivenciamos, deixa profundas dívidas de identidade na formação de professores e estudantes de todas as áreas do conhecimento.

Há que se criar uma cultura que inclua a perspectiva da filosofia africana "Ubuntu", onde conceitos como humanidade incluem necessariamente cordialidade, fraternidade, igualdade, justiça (dar a cada um o que lhe corresponde). Uma cultura onde a humanidade construa uma relação de família, onde seja superado o processo de escravização, opressão, 
exclusão, desumanização que domina os currículos escolares em geral. Pois entendemos que uma família não é um clube onde se escolhe entrar ou sair. A família é onde nascemos, é o local onde todos têm o direito de exercer sua humanidade: a soberania, a liberdade, a criatividade, o poder pessoal, sua unicidade e dignidade como membro essencial da família humana. Tais valores em nossa perspectiva devem estar contidos nos currículos das escolas desde a educação infantil à pós-graduação. Uma vez que há cinco séculos o sistema hegemônico vem investindo na invisibilidade das matrizes históricas e culturais que dão sentido e significado à maneira de ser e de viver de povos não europeus que tiveram seus territórios invadidos e conquistados. Talvez sejam necessários mais cinco séculos para dar visibilidade a todas as culturas do conjunto de povos que integram a humanidade.

O intercâmbio cultural continuará a enriquecer a qualidade da vida humana no planeta terra. Todas as culturas são ricas e importantes para o bem viver de todos os seus integrantes. A reforma dos currículos da educação escolar incluindo igual valorização da história e cultura dos povos em geral é um imperativo de verdade histórica e respeito às importantes contribuições de todas as civilizações humanas para o bem comum. Eis o desafio. Que as lideranças acadêmicas das universidades reflitam sobre a inserção significativa das histórias da humanidade no currículo. E, por outro lado a criação de linhas de pesquisa para obter uma verdadeira formação integral humana contribuindo para construir a sociedade igualitária, livre, soberana onde a criatividade e o bem comum sejam o campo de atuação de todos os seres humanos, onde a interdependência seja um valor a ser desenvolvido em cada ser humano em prol do bem comum.

\section{REFERÊNCIAS}

BALLESTRIN, Luciana. A américa Latina e o giro decolonial. Revista Brasileira de Ciência Política, nº11. Brasília, maio - agosto de 2013, pp. 89-117.

CASANOVA-GONAZÁLES, Pablo. De la sociología del poder a la sociología de la explotación : pensar América Latina en el siglo XXI /Siglo XXI Editores ; Buenos Aires : CLACSO ; 2015.

CASTRO. Josefina Granja. El pensar sistémico. Metapolitica, Volumen 5, octubre/diciembre, 2001, pág. 90-115. ISSN 1405-4558.

CORONA, Sarah. La asignatura ciudadana en las cuatro grandes reformas de LTG en México (1954-2010). México: siglo XXI. 2015

FANON, Franz. Pele negra máscaras brancas. Salvador: Editora da UFBA. 2008 
Os condenados da terra. Juiz de Fora: Editora UFJF, 2010.

GRANDO, Beleni Saléte, PINHO, Vilma Aparecida de Pinho; RODRIGUES, Eglen Silvia Pipi. Metodologia intercultural na formação - ação para a Educação infantil: a cultura bororo e as relações Étnico - raciais. Laplage em Revista (Sorocaba), vol.4, n. Especial, set. - dez. 2018, p.86-101

GROSFOGUEL, Ramón. Del "extractivismo económico" al "extractivismo epistémico" y al "extractivismo ontológico": una forma destructiva de conocer, ser y estar en el mundo. Tabula Rasa. Bogotá - Colombía, No. 24, 123-143-, Enero-junio, 2016. ISSN 1794-2489.

KAKOZI KASHINDI Jean-Bosco. Ubuntu como vivencia del humanismo africano bantú, disponível en:

https://www.academia.edu/26780326/Ubuntu_como_vivencia_del_humanismo_africano_bant u? auto=download. 2012. Acesso: 11/9/2019.

LEÓN-PORTILLA, Miguel. Visión de los vencidos relaciones indígenas de la conquista, $28^{a}$ edición, Universidad Nacional Autónoma de México, ciudad de México, DF, 2006.

MARTÍNEZ, Regina. The different faces of mestizaje: ethnicity and race in Mexico. En E. Telles y PERLA (Project on Ethnicity and Race in Latin America), Pigmentocracies: ethnicity, race and color in Latin America. Estados Unidos: The University of North Carolina Press. 2014, pag. 36-80.

MASCARENHAS, S. A. DO N. Avaliação longitudinal de variáveis cognitivas e contextuais do ensino superior analisando seus efeitos sobre o bem estar e o rendimento acadêmico, Base de dados, Brasil/México, PROCAD/AMAZÔNIAPPGEUFAM/UFPA/UFMT, Processo CAPES 8881.314288/2019-0, Não publicado, 2019 O`SHEA, Janet. Decolonizar o currículo? Possibilidades para desestabilizar a formação em performance, 2018. Rev. Bras. Estud. Presença, Porto Alegre, v. 8, n. 4, p. 750-762, out./dez. 2018. Disponível em: <http://dx.doi.org/10.1590/2237-266078871. Acesso: $15 / 8 / 2019$.

RAMOSE, Mogobe B. African Philosophy through Ubuntu. Harare: Mond Books, 1999, p. 49-66.

RODNEY, Walter, Como Europa subdesarrollo a África, Editorial de ciencias sociales, Ciudad de La Habana, 1981.

SEN. Amartya. Desenvolvimento como liberdade, São Paulo, Companhia das Letras, 2010. SILVA. Roberto R. D. da. Revisitando a noção de justiça curricular: problematizações ao processo de seleção dos conhecimentos escolares. EDUR: Educação em Revista. 2018; 34:e168824. DOI: http://dx.doi.org/10.1590/0102-4698168824

TUCK, Eve; YANG, K. Wayne. Decolonization is Not a Metaphor. Decolonization: Indigeneity, Education, and Society, Toronto, University of Toronto, v. 1, n. 1, p. 1-40, 2012. 
TRUEBA. César Carrillo. El racismo en México. Una visión sintética. Ciudad de México: EDIMPRO, S.A, 2009.

VICH, Víctor. Desculturalizar la cultura. La gestión cultural como forma de acción política. Argentina: Siglo XXI Editores. 2014

VILLAVICENCIO SANTILLÁN., Washington, Las características del currículo colonizado desde una perspectiva teórico-social. YACHANA Revista Científica, vol. 5, núm. 2 (juliodiciembre de 2016), pp. 77-86.2016.

\section{Agradecimentos:}

CAPES/MEC/Brasil/Programa PROCAD/AMAZONIA, CAPES (ref. 8881.314288/2019-0);

Às universidades que colaboram com a investigação, aos investigadores colaboradores;

Aos estudantes, docentes e técnicos que integram a amostragem;

Recebido em: 28/10/2019

Aprovado em: 30/11/2019 